\title{
Polyp Surveillance
}

\author{
W. Donald Buie, M.D. ${ }^{1}$ and Anthony R. MacLean, M.D. ${ }^{1}$
}

\begin{abstract}
Surveillance after colonic polypectomy is important to detect and remove missed synchronous polyps and cancers and new metachronous polyps or cancers. The authors review methods of surveillance and the risk of recurrent adenomas and provide surveillance recommendations.
\end{abstract}

KEYWORDS: Polyp, polypectomy, surveillance, screening

Objectives: Upon completion of this article, the reader should be familiar with methods of polyp surveillance, the risk of recurrent adenomas, and surveillance recommendations.

Colorectal cancer is the second leading cause of cancer-related mortality in North America. Most cases of colorectal cancer progress through the adenoma to carcinoma sequence, allowing an opportunity for screening and prevention.

Recently, there has been an increased emphasis on screening for colorectal cancer, with education programs directed at the public, primary care physicians, gastroenterologists, and surgeons. Several groups have published guidelines for colorectal cancer screening, and these strategies have served to increase the number of screening colonoscopies being performed with a resultant increase in the number of polyps identified.

When a polyp is identified, it is generally removed to establish its histology, to rule out malignancy, and to establish the subsequent risk of a metachronous polyp or cancer. About $60 \%$ of polyps are adenomatous. Adenomas are by definition dysplastic, and therefore have a risk of malignant transformation. Adenomas have an increased prevalence with advancing age. Approximately 25 to $30 \%$ of patients aged 50 will have an adenoma, increasing to as high as $50 \%$ by age $70 .{ }^{1-3}$ Removal of these adenomas at colonoscopy has been shown to decrease the incidence of colorectal cancer by 76 to $90 \% .{ }^{4,5}$
Following removal of an adenoma, patients are generally placed in a surveillance program to detect and remove missed synchronous polyps or cancers and new metachronous polyps or cancers.

The purpose of this review is to describe the current recommended approach to the surveillance of patients who have undergone a polypectomy.

\section{METHODS OF SURVEILLANCE}

\section{Colonoscopy}

Colonoscopy is the primary method of postpolypectomy surveillance. It is the only method that allows direct visualization of the colonic mucosa in its entirety for screening and surveillance, with biopsy for definitive diagnosis. It also has the potential for definitive treatment through polypectomy. It is presently the gold standard, as a positive result on all other screening tests requires a colonoscopy as a secondary procedure for confirmation and possible intervention. Patients are required to undertake a complete mechanical bowel preparation. Following intravenous sedation, the colonoscope is introduced into the anus and advanced to the

${ }^{1}$ Department of Surgery, University of Calgary, Calgary, Alberta, Canada.

Address for correspondence and reprint requests: W. Donald Buie, M.D., Department of Surgery, Foothills Medical Centre, 1403-29 St. NW, Calgary, Alberta, T2N 2T9, Canada (e-mail: wdbuie@ucalgary.ca).

Polyps and Polyposis Coli; Guest Editor, Janice F. Rafferty, M.D.

Clin Colon Rectal Surg 2008;21:237-246. Copyright (C) 2008 by Thieme Medical Publishers, Inc., 333 Seventh Avenue, New York, NY 10001, USA. Tel: +1(212) 584-4662.

DOI 10.1055/s-0028-1089938. ISSN 1531-0043. 
cecum. The scope is withdrawn and the mucosa is carefully evaluated. In general, all identified polyps are removed.

There are several advantages to colonoscopy. In addition to complete evaluation of the colonic mucosa and definitive treatment through polypectomy, it is an outpatient procedure that is well tolerated. It has been shown to be preferred over flexible sigmoidoscopy, which is undertaken in a patient who is nonsedated. ${ }^{6}$ Disadvantages include the need for a full bowel preparation, its invasive nature, and the need for transportation following the procedure due to sedation. Risks include perforation and bleeding, especially with polypectomy. The risk of perforation has been estimated at 1 in 1000 in several recent trials. ${ }^{7,8}$ This risk increases with age and the presence of diverticular disease. Bleeding risk increases with large polyps, thick stalks, and multiple polyps. Other complications include allergic reactions and cardiopulmonary complications usually related to sedative medications. ${ }^{9}$ Although these complications are rare, they become more significant in large screening programs where an absolute increase in secondary admissions, investigations, and surgery is realized.

No prospective randomized controlled trials (RCT) have directly investigated the effect of screening colonoscopy on the incidence of colorectal cancer (CRC) or the mortality associated with CRC. However, colonoscopy and colonoscopic polypectomy is used as the gold standard in most RCTs of other screening tests, providing indirect evidence for its efficacy. A RCT of fecal occult blood testing (FOBT) from Minnesota demonstrated a 20\% reduction in the incidence of colorectal cancer, which was attributed by the authors to follow-up colonoscopy and polypectomy in patients who had a positive FOBT. ${ }^{10}$ In a RCT of flexible sigmoidoscopy versus no screening, an $80 \%$ reduction in the incidence of $\mathrm{CRC}$ was observed. Again this was attributed to follow up colonoscopic polypectomy in those patients with polyps identified on flexible sigmoidoscopy. ${ }^{11}$

Further indirect evidence comes from two studies of adenoma clearance. Following clearance colonoscopy, these large cohorts demonstrated a reduction in the incidence of colorectal cancer when compared with reference populations ranging from 75 to $90 \%$ and $80 \%$, respectively. ${ }^{4,5}$ On the other hand, several chemoprevention trials and dietary intervention trials have not shown a reduction in CRC incidence following clearing colonoscopy. ${ }^{12-14}$ The reason for this discrepancy is not clear, but may be due to differences in patient populations, polyp inclusion criteria, and the overall quality of colonoscopies. ${ }^{15}$

The efficacy of postpolypectomy surveillance is dependent on the quality of the initial colonoscopy, which, in turn, depends on several variables including bowel preparation, redundancy, angulation of the colon and finally skill and thoroughness of the colonoscopist. A high-quality colonoscopy, as defined by the United States Multi-Society Task Force on Colorectal Cancer (USMTF), requires an adequate bowel preparation with minimal fecal residue, reaches the cecum with good visualization and includes a minimum withdrawal time of 6 to 10 minutes from the cecum. ${ }^{9}$ Although recognized as the gold standard, colonoscopy has a recognized miss rate for adenomas, advanced adenomas, and cancers, ${ }^{16-19}$ especially for right-sided lesions. The miss rate for large adenomas of $10 \mathrm{~mm}$ or more is estimated at 6 to $12 \%,{ }^{20,21}$ whereas the estimated miss rate for cancer is $\sim 5 \% .^{20,21}$

A poor quality colonoscopy without reliable clearance of adenomas will have a miss rate that exceeds these accepted norms placing even a low-risk patient at higher risk of future metachronous advanced adenomas and carcinomas. Thus, the quality of baseline colonoscopy in a surveillance program is an important variable for subsequent neoplasia. RCTs, where quality control of colonoscopy was very uniform such as the National Polyp Study, have demonstrated the greatest reduction in subsequent polyps and cancer incidence. ${ }^{4,22}$ In these studies, a significant percentage of patients underwent a second colonoscopy if the initial visualization was not adequate. Studies with less stringent adherence to colonoscopic quality control have demonstrated higher miss rates. ${ }^{16}$ Up to $50 \%$ of subsequent cancers in the pooled Dietary Polyp Prevention Trial could have been prevented or detected earlier with better quality control of baseline colonoscopy clearance. ${ }^{12,23}$ Failure of baseline clearance results in a higher than expected incidence of colorectal tumors in the first 6 months to 4 years. These so-called early failures can be used as a surrogate marker for quality of baseline colonoscopy. In a large adenoma detection study from Holland, the incidence of colorectal cancer was not reduced until 6 years after the start of the trial. ${ }^{24}$

Incomplete removal of sessile lesions or inadequate piecemeal excision results in early recurrence and a higher incidence of metachronous colorectal cancers. ${ }^{12,23} \mathrm{Up}$ to $25 \%$ of interval cancers may be due to incomplete polypectomy. ${ }^{23,25}$ Atkin et $\mathrm{al}^{26}$ in a sigmoidoscopy trial demonstrated that inadequate removal of sessile rectosigmoid adenomas at baseline led to an increased incidence of subsequent rectal cancer.

The consensus of evidence is that colonoscopy and colonoscopic polypectomy decreases the incidence of colorectal cancer. However, the magnitude of this effect is not known. The greatest benefit appears to be from the initial colonoscopy. ${ }^{9,27}$ A population study of 35,000 patients from Manitoba were followed for 10 years following a negative colonoscopy. ${ }^{28}$ Although there were significant reductions in CRC incidence over time, which were sustained for 10 years, the 
incidence reductions were less than expected for each of the first 5 years. Early cancers found between 6 months and 5 years were predominantly right sided suggesting difficulty in clearing the right colon and emphasizing again the importance of quality especially of the index procedure.

\section{High-Magnification Chromoendoscopy}

Although colonoscopy is the primary method of postpolypectomy surveillance, several other promising technologies are emerging that may have a place in the surveillance algorithm. Chromoendoscopy involves dye spray of the mucosa followed by examination by magnification endoscopy. This technique may improve the detection of small or flat colorectal lesions by enhancing subtle changes in the mucosal architecture: the loss of vascular net pattern, focal pallor or erythema, hemorrhagic spots, fold convergence, and marginal irregularity or mucosal unevenness. Following initial visualization by conventional videocolonoscopy, suspicious areas are washed down, sprayed with dye, and examined using magnification at up to 150 times normal. Examination of the details in mucosal morphology has resulted in recognition of optical pit patterns and crypt architecture associated with more advanced lesions. ${ }^{29}$

High-magnification chromoendoscopic colonoscopy may have a role in the detection of nonpolypoid colorectal lesions in high-risk patients. Although most colorectal cancers arise from adenomatous or villous polyps, up to one-third of cancers may develop from flat or depressed lesions, so-called flat adenomas. Muto and colleagues ${ }^{30}$ have described these lesions as flat or slightly elevated, usually less than $10 \mathrm{~mm}$ in size, sometimes with an associated central depression and often reddish in color. Most flat adenomas have tubular rather than villous architecture on histology. In a study by Hurlstone, 25\% of 458 flat lesions that were removed had foci of high-grade dysplasia with the majority of these lesions located in the right colon. ${ }^{31}$ In contrast, polypoid lesions recovered from the same patient population demonstrated high-grade dysplasia in only $12 \%$ of the adenomas, $95 \%$ of which were located in the left colon. Several other studies have also demonstrated that flat and depressed lesions are more advanced and contain both high-grade dysplasia and cancer more often than similar-sized polypoid lesions. ${ }^{32,33}$

Although chromoendoscopy appears to improve the detection of flat adenomas, its efficacy in screening or surveillance programs has yet to be demonstrated and it is not routinely recommended for postpolypectomy surveillance. Nonetheless, it may improve the diagnostic yield of biopsies by decreasing the number of insignificant lesions that are sent for pathologic evaluation improving the efficiency of screening large populations. The technique is credited with an increasing proportion of early-stage colorectal cancers being diagnosed in Japan. ${ }^{34}$ Although it is difficult to extrapolate these results to Western populations, further research is warranted to establish the utility of this technique.

\section{Narrow Band Imaging}

Narrow band imaging (NBI) is a high-resolution endoscopic technique that enhances the fine structure of the mucosal surface without dye. Narrow band filters are placed in front of a conventional white light source to illuminate tissue at two selected narrow band widths $415 \mathrm{~nm}$ (blue) and $540 \mathrm{~nm}$ (green). The bands are chosen to obtain the greatest contrast between vascular patterns in the mucosa and correspond to the primary and secondary peaks on the absorption spectrum of hemoglobin. Structures with high hemoglobin content absorb light and appear darker in contrast to the surrounding mucosa, which reflects light. The reflected light allows visualization of the superficial architecture of the mucosa and enhances the epithelial microvascular pattern. ${ }^{35}$ The characteristic appearance of a neoplastic lesion in NBI is a brown blob under low magnification. Under high magnification a unique vascular pattern with surface pits is visible.

There are three prospective studies comparing NBI with chromoendoscopy. ${ }^{36-38}$ In all studies, the two modalities are comparable and superior to standard white light colonoscopy for polyp differentiation. The diagnostic accuracies for differentiating adenomas from nonadenomatous lesions ranged from 87 to $97 \%$ for NBI, 91 to $93 \%$ for chromoendoscopy and 67 to $82 \%$ for standard white light exams (WLE). Two randomized controlled trials compared NBI without magnification to WLE during withdrawal. ${ }^{39,40}$ Neither demonstrated an increase in detection rate. Whether NBI can improve detection rates in colonoscopists with low rates of polyp detection is unclear. A study by East et $\mathrm{al}^{41}$ examined back-to-back colonoscopy in 62 patients with hereditary nonpolyposis colorectal cancer (HNPCC). NBI was used in the second pass and demonstrated a significant increase in the detection rate of adenomatous lesions from 25 to 46 adenomas. This single trial requires further study in a prospective controlled manner for confirmation of the results. Chiu et $\mathrm{al}^{37}$ recently published a comparative study between NBI and chromoendoscopy with and without magnification. NBI with magnification demonstrated a higher specificity, whereas chromoendoscopy with magnification demonstrated a higher sensitivity. The two modalities may complement each other and thus may be additive. At the present time, accepted diagnostic criteria for colorectal lesions with correlation of images and pathology remains to be established and validated. However, this remains a promising adjunct to conventional colonoscopic surveillance. 
A related technology called multiband imaging uses software to digitally enhance the images by selecting out specific band widths and constructing a virtual image of a single wavelength. Three single wavelength images are selected and sent to the red, green, and blue monitor inputs to display a composite color-enhanced MBI image in real time. There are no published data on the efficacy of MBI for the detection or differentiation of colonoscopic polyps.

\section{Computed Tomography Colonography}

Computed tomography colonography (CTC) sometimes called virtual colonoscopy is the newest modality for visualization of the colon. Its place within surveillance and screening algorithms has yet to be completely determined. However the most recent joint guideline from the American Cancer Society (ACS), USMSTF, and the American College of Radiology (ACR) included CTC as a potential screening and surveillance modality for colorectal cancer and adenomatous polyps. ${ }^{15}$

Multiplanar CT images are obtained using thin 1to 2-mm slice collimation. The images are enhanced with software to create two- (2D) and three-dimensional (3D) displays of the entire colon allowing identification of neoplastic lesions. The procedure requires a cathartic bowel preparation similar to colonoscopy and gaseous distension with a small rectal catheter for visualization. Radiographic labeling of residual solid stool and fluid with oral contrast agents is used to improve visualization. No sedation is given and the procedure takes $\sim 10$ minutes to complete although interpretation may take longer.

There are no RCTs examining the efficacy of CTC in reducing CRC mortality. Studies to date have focused on the identification of advanced adenomas and cancer. Initial trials demonstrated a sensitivity for large polyps of 55 to $59 \%$ when compared with colonoscopy. ${ }^{42,43}$ In a more recent study by Pickhardt et al, 1233 asymptomatic adults were screened for neoplasia using 3D imaging with oral contrast agents. ${ }^{44}$ Sensitivity when compared with colonoscopy was $89 \%$ for adenomas $\geq 6 \mathrm{~mm}$.

Two early meta-analyses examining the overall performance of CTC included both high-risk and average-risk patients. ${ }^{45,46}$ The pooled sensitivity and specificity for large polyps $>1 \mathrm{~cm}$ in size was found to be 85 to $93 \%$ and 85 to $96 \%$, respectively.

A recent meta-analysis by Rosman published in 2007 reported a sensitivity of $0.82(\mathrm{CI}=0.76$ to .88$)$ for polyps $>10 \mathrm{~mm}, 0.63(\mathrm{CI}=0.52$ to .75$)$ for polyps 6 to $10 \mathrm{~mm}$, and $0.56(\mathrm{CI}=0.42$ to .70$)$ for polyps 0 to $5 \mathrm{~mm}$. At a threshold of $5 \mathrm{~mm}$, the accuracy of endoscopic colonoscopy was higher when compared with CTC. However, CTC was more accurate than barium enema. The authors concluded that although reasonably sensitive and specific for large polyps CTC is not as accurate as colonoscopy. ${ }^{47}$
In addition to diagnostic accuracy, several other overriding issues remain including cost and safety. A recent article published by $V_{i j a n}$ et $\mathrm{al}^{48}$ examined the cost effectiveness of 2D and 3D CTC as a screening test for detecting polyps and cancers. Using a Markoff model, CTC every 5 or 10 years was effective and cost-effective relative to no screening. However, it was more expensive and less effective than colonoscopy. To be cost effective within this model, the diagnostic accuracy needed to be higher than $83 \%$ and the cost around $60 \%$ of the cost of colonoscopy. The authors concluded that cost effectiveness of CTC requires improvements in present technology.

Another important issue is radiation exposure. Although decreasing with improvements in technology, the long-term effect of repeated exposure over a long period is not entirely understood. Additional factors include limited access and expertise at the present time. The procedure appears to be highly operator dependent with respect to interpretation. A positive or suspicious test requires a follow-up colonoscopy. In some centers, same-day colonoscopy can be offered for patients with abnormalities seen on CTC.

Although great progress has been made with respect to CTC in the past 10 years it cannot as yet supplant colonoscopy as a primary surveillance modality. At the present time it is useful for patients who cannot undergo a complete colonoscopy for technical reasons, for patients in whom colonoscopy is contraindicated and in patients who refuse colonoscopy. In the future, with improvements in technology CTC may be used for surveillance of a specific subpopulation alone or in combination with colonoscopy, perhaps as follow up to an index colonoscopy in a low-risk patient.

\section{Barium Enema}

Although barium enema is still included as a potential method for postpolypectomy surveillance, it has a limited role. It requires a full bowel preparation. It is not as sensitive for small polyps or flat adenomas as colonoscopy and visualization of a suspicious lesion must be followed by colonoscopy. It has been used to examine the remaining colon when colonoscopy cannot be completed for technical reasons. This role has largely been supplanted by CTC in many centers. CTC has demonstrated greater efficacy than barium enema. ${ }^{35}$ As CTC use increases, the technical and interpretive experience with contrast enemas is expected to decline among radiologists, which may further limit its use.

\section{RISK OF RECURRENT ADENOMA}

Several studies have sought to determine the risk of a subsequent adenoma following removal of an adenomatous polyp. Although there are conflicting results about 
the importance and/or statistical significance of the assessed risk factors, the risk seems to be elevated with the presence of several of the following factors: (1) presence of more than three adenomas on baseline colonoscopy, (2) adenomatous polyp size $>1 \mathrm{~cm}$, (3) adenomatous polyps with villous histology ( $>75 \%$ villous component), (4) adenomatous polyp with highgrade dysplasia; and (5) malignant polyps. The presence of a proximal colonic adenoma (located proximal to the splenic flexure) was also found to be an important risk factor in some studies. Several studies have also assessed these factors for the development of an advanced neoplasm, again with varying results.

In addition, the risk appears to be markedly elevated in patients with sessile polyps that are removed piecemeal or with endoscopic submucosal resection, patients with more than 10 adenomas, and those with a family history consistent with HNPCC or Lynch syndrome.

Based on available knowledge of the subsequent risk of neoplasia, patients with polyps excised can be classified into low and higher risk groups.

\section{Low-Risk Polyps}

Polyps with a low risk of subsequent neoplasia include hyperplastic polyps and small tubular adenomas with no high-grade dysplasia.

\section{HYPERPLASTIC POLYPS}

Hyperplastic polyps are the most common nonneoplastic polyps found in the colon and rectum. They do not exhibit dysplasia, and feature a characteristic "sawtooth" appearance on histology. Patients with small hyperplastic polyps do not have an increased risk of subsequent neoplasia, and should be considered to have had a normal colonoscopy. Their subsequent follow-up should be based on established guidelines based on their underlying risk factors, such as prior colonoscopy findings or a family history of colorectal cancer.

An exception to this is in patients who have multiple, large, and /or proximal hyperplastic polyps. These patients may have hyperplastic polyposis syndrome, defined by Burt and Jass ${ }^{49}$ as (1) at least five histologically confirmed hyperplastic polyps proximal to the sigmoid, of which two are $>1 \mathrm{~cm}$; (2) any number of hyperplastic polyps occurring proximal to the sigmoid colon in patients with a first-degree family history of hyperplastic polyposis; or (3) 30 or more hyperplastic polyps distributed anywhere in the colon and rectum. These patients have an increased risk of subsequent neoplastic development. The natural history of hyperplastic polyposis syndrome is not well characterized, but most authors recommend an increased frequency of colonoscopic surveillance. ${ }^{50}$

\section{TUBULAR ADENOMAS}

Tubular adenomas account for $\sim 80 \%$ of colorectal adenomas. Tubular adenomas are comprised of at least $75 \%$ tubular component. Patients with one or two tubular adenomas $<1 \mathrm{~cm}$ and with no high-grade dysplasia have either no increased risk, ${ }^{51}$ or only a slightly increased risk of subsequent neoplasia, and thus their screening interval should again be based largely on their underlying risk factors.

\section{Higher Risk Polyps}

Higher risk individuals include those with more than three adenomas, adenomas with villous histology, large adenomas $>1 \mathrm{~cm}$, adenomas with high-grade dysplasia, malignant polyps, proximally located adenomas, sessile adenomas that are removed piecemeal, and patients with a family history compatible with HNPCC.

\section{NUMBER OF ADENOMAS}

Several studies have examined the importance of multiple adenomas as a predictor for subsequent adenoma formation. In patients in whom three or more adenomas are excised, the risk of subsequent neoplasia and advanced neoplasia has been shown to be increased in many of those studies. ${ }^{22,52-59}$ RCTs that have assessed this issue include the National Polyp Study, ${ }^{22}$ the European Fiber-Calcium Intervention Trial, ${ }^{57}$ a study ${ }^{12}$ using pooled data from an antioxidant vitamin polyp prevention trial, ${ }^{60}$ a calcium polyp prevention trial, ${ }^{61}$ and an aspirin polyp prevention trial. ${ }^{62}$ The last three studies demonstrated that multiple polyps increased the subsequent risk of adenomas. In contrast, a recent study which looked at the data from the Polyp Prevention Trial $^{14}$ and a previous follow-up study on patients in the Wheat Bran Fiber (WBF) trial showed no statistically significant association of adenoma number and the risk of subsequent advanced adenomas. ${ }^{54}$

Cohort studies by Atkin et al, ${ }^{63}$ Noshirwani et al, ${ }^{64}$ and Lieberman et a ${ }^{58}$ demonstrated an increased risk of metachronous adenomas following a finding of more than one adenoma on initial sigmoidoscopy ${ }^{63}$ or colonoscopy. In Lieberman's study, even if there were no adverse gross or histologic features (size $>1 \mathrm{~cm}$, sessile histology, high-grade dysplasia), the risk of subsequent neoplasia after finding three or more adenomas was $\sim 11.9 \%$ at 5.5 years. ${ }^{58}$

In cases where more than 10 adenomas are found, the possibility of a genetic syndrome should be entertained, and close follow-up is warranted.

\section{LARGE ADENOMAS}

Several studies have shown that patients with adenomas $>1 \mathrm{~cm}$ in size have a higher risk for the development of subsequent adenomas $22,53-55,59,65$ and/or advanced neoplasms. ${ }^{53,54,59,63,64,66,67}$ Of the randomized controlled 
trials, only the Wheat Bran Fiber Trial ${ }^{54}$ demonstrated an increased risk of metachronous advanced adenomas after removal of an adenoma $>1 \mathrm{~cm}$. There was no statistically significant difference seen in the other RCTs.

Cohort studies by Yang et $\mathrm{al}^{53}$ and Lieberman and colleagues ${ }^{58}$ showed that patients with a baseline polyp $>1 \mathrm{~cm}$ had an increased risk of metachronous advanced neoplasia, with a relative risk of 4.4 and 6.4, respectively. In Lieberman's study of 1171 veterans who underwent colonoscopy and polypectomy at baseline, patients with a baseline polyp $>1 \mathrm{~cm}$ had a risk of subsequent advanced neoplasia at 5.5 years of $15.5 \% .^{58}$

\section{ADENOMAS WITH VILLOUS HISTOLOGY}

A few studies have shown that patients who are found to have an adenoma with villous or tubulovillous histology have an increased risk of subsequent adenomas $52,53,56,65$ and advanced neoplasms. ${ }^{24,53,59,63}$ Although none of the RCTs showed villous histology to be a significant predictor of subsequent advanced neoplasia, cohort studies by Atkin et al, ${ }^{63}$ Yang et $\mathrm{al}^{, 53}$ and Loeve et $\mathrm{al}^{24}$ did show an increased risk. Interobserver variability in the diagnosis of a villous adenoma may affect the results of those studies.

\section{ADENOMAS WITH HIGH-GRADE DYSPLASIA}

Although none of the RCTs showed high-grade dysplasia to be a significant predictor of subsequent advanced neoplasia, this factor was predictive in some of the cohort studies. Patients with high-grade dysplasia found in a resected polyp were shown to be at higher risk of subsequent adenomas ${ }^{53,65}$ and/or adenomas with high-grade dysplasia or cancer. ${ }^{53,58,59,63}$ The Veteran's Administration study by Lieberman et al demonstrated an increased risk of a metachronous adenoma with highgrade dysplasia or cancer in patients who had a polyp with high-grade dysplasia removed. The risk in that group was $16 \%$ over 5 years, compared with $4.6 \%$ in those with small tubular adenomas. ${ }^{58}$

\section{MALIGNANT POLYP}

There is not a lot of data that looks specifically at this subset of patients, though one can extrapolate from studies that indicate advanced neoplasms at primary colonoscopy predict for metachronous advanced neoplasms, indicating that these patients are at increased risk. The Lieberman study showed that the risk of a metachronous adenoma with high-grade dysplasia or cancer was $\sim 35 \%$ in patients with a cancer at baseline colonoscopy.

\section{PROXIMALLY LOCATED ADENOMAS}

Two RCTs demonstrated that proximal adenomas at baseline were associated with an increased risk of meta- chronous advanced adenomas. ${ }^{54,57}$ Most studies did not report specifically on this issue.

\section{PIECEMEAL EXCISION OF LARGE ADENOMA}

Patients undergoing piecemeal excision of large sessile adenomas have an increased risk of both local recurrence and subsequent neoplasia. The risk of local recurrence depends largely upon the completeness of the excision, but is in the range of $30 \%$. Seventeen percent of the patients later degenerated into carcinoma despite what appeared to be a complete excision. $^{68}$

\section{ENDOSCOPIC MUCOSAL RESECTION}

Patients who undergo endoscopic mucosal resection (EMR) of sessile colorectal polyps have an increased risk of recurrent adenoma, and require close follow-up. At 6 months of follow-up, the recurrence rates seen in three studies have been 10 to $17 \% .^{69-71}$

\section{ARGON PLASMA COAGULATION FOLLOWING POLYPECTOMY}

A study by Brooker et $\mathrm{al}^{72}$ demonstrated that following piecemeal polypectomy of large sessile polyps, application of argon plasma coagulation (APC) was associated with a decreased risk of recurrence compared with piecemeal polypectomy alone at their 3month follow-up colonoscopy. Although this technique is promising, there are currently insufficient data to show that the risk of metachronous neoplasia is significantly different, or that follow-up strategies should be altered.

\section{RECOMMENDATIONS}

Current surveillance recommendations are centered on risk stratification based on the findings at initial colonoscopy and family history. They are predicated on a high-quality baseline examination with complete clearance of the colon and complete excision of all polyps. Provided these criteria are met, surveillance intervals for many patients can be extended allowing concentration of resources on those at higher risk. Patients at higher risk based on the criteria outlined in the previous section require colonoscopic surveillance at shorter intervals. On the other hand, frequent colonoscopies in low-risk patients expose them to a small, but real risk of complications while having a negligible impact on reducing the risk of metachronous lesions.

Several recent publications have outlined criteria for good colonoscopy practice. $9,73,74$ The recent guideline, "Screening and Surveillance for the Early Detection of Colorectal Cancer and Adenomatous Polyps" published jointly by the American Cancer Society (ACS), the USMTF, and American College of Radiology in 
2008 summarized the following criteria for a highquality colonoscopy surveillance program ${ }^{15}$ :

1. Appropriate training and experience

2. Proper documentation of risk assessment

3. Complete exam of the cecum with adequate mucosal visualization and bowel preparation

4. Ability to detect and remove polyps safely

5. Documentation of polypoid lesions and methods for removal

6. Timely and appropriate management of adverse events

7. Appropriate follow-up for histopathology findings

8. Appropriate recommendation for surveillance or repeat screening based on published guidelines. ${ }^{15}$

As outlined in the guidelines all surveillance programs should be involved in a continuous quality improvement process. This ensures that standards are being met and there is continuous improvement in process and outcome.

The most current guidelines from the ACS, the USMSTF, and the ACR are summarized in Table $1 .^{50}$ There are three risk categories including low, moderate, and high risk. Low-risk patients include those with hyperplastic polyps and one or two small adenomas with low-grade dysplasia. Patients with hyperplastic polyps are considered to have normal colonoscopies and provided they do not have a family history of CRC should be considered for follow-up in 10 years.
Patients with small adenomas require follow-up colonoscopy in 5 to 10 years based on previous colonoscopy findings, family history, and clinical judgment. The moderate risk category includes patients with 3 to 10 adenomas, large adenoma or advanced adenomas with villous features, or high-grade dysplasia. In these patients, the initial follow-up interval is shortened to 3 years. If the subsequent examination is low risk or normal, it can be extended to 5 years. Patients with more than 10 adenomas or sessile adenomas removed piecemeal require closer follow-up as outlined. It should be stressed that piecemeal removal requires very close follow-up at 2 to 6 months, as there is a high recurrence rate. Once complete removal has been verified both endoscopically and pathologically, the patient can revert to a less intense follow-up based on family history and clinical judgment.

Patients who are suspected of having HNPCC or AFAP (attenuated familial polyposis) should follow previously published guidelines for each respective syndrome and consider genetic testing with counseling. Patients with hyperplastic polyposis syndrome are also at increased risk for colonic adenomas and cancer and should also undergo more frequent surveillance, although the optimal screening protocol is not known.

Once patients are entered into a screening program they tend to continue on indefinitely. The current recommendations suggest discontinuing surveillance in any patient with serious comorbidities who has less than

Table 1 Postpolypectomy Surveillance Recommendations*

\begin{tabular}{|c|c|c|c|}
\hline Risk Category & & Colonoscopy Interval & Comments \\
\hline \multirow[t]{2}{*}{ Low risk } & Small hyperplastic rectal polyps & 10 years & $\begin{array}{l}\text { Be aware of hyperplastic polyposis syndrome, } \\
\text { which needs more intensive follow-up }\end{array}$ \\
\hline & $\begin{array}{l}1 \text { or } 2 \text { small adenomas }(<1 \mathrm{~cm}) \\
\text { with low-grade dysplasia }\end{array}$ & $5-10$ years & $\begin{array}{l}\text { Precise timing is based on clinical factors } \\
\text { such as prior colonoscopy findings, } \\
\text { family history, preferences of the patient, } \\
\text { and judgment of the physician. }\end{array}$ \\
\hline Moderate risk & $\begin{array}{l}\text { 3-10 adenomas } \\
\text { Adenoma } \geq 1 \mathrm{~cm} \\
\text { Adenomas with villous features } \\
\text { High-grade dysplasia }\end{array}$ & 3 years & $\begin{array}{l}\text { If follow-up colonoscopy is normal or } \\
\text { shows only } 1 \text { or } 2 \text { small tubular } \\
\text { adenomas with low-grade dysplasia, } \\
\text { then the subsequent examination should be } \\
\text { in } 5 \text { years. If piecemeal removal or } \\
\text { incomplete removal see below }\end{array}$ \\
\hline \multirow[t]{3}{*}{ High risk } & $>10$ adenomas & $<3$ years & $\begin{array}{l}\text { Based on clinical judgment Consider } \\
\text { familial syndrome }\end{array}$ \\
\hline & $\begin{array}{l}\text { Sessile adenomas removed } \\
\text { piecemeal }\end{array}$ & $\begin{array}{l}\text { 2-6 months to verify } \\
\text { complete removal }\end{array}$ & $\begin{array}{l}\text { Subsequent surveillance individualized } \\
\text { Complete removal based on endoscopic } \\
\text { and pathologic assessments }\end{array}$ \\
\hline & $\begin{array}{l}\text { Family history consistent with } \\
\text { HNPCC }\end{array}$ & $\begin{array}{l}\text { Colonoscopy at 1- to } \\
\text { 2-year intervals, consider } \\
\text { genetic testing }\end{array}$ & See guidelines for HNPCC \\
\hline
\end{tabular}

${ }^{*}$ Adapted from Levin et al. ${ }^{15}$ HNPCC, hereditary nonpolyposis colorectal cancer. 
10 years life expectancy. ${ }^{37}$ With increasing age, colonoscopy gives diminishing returns while exposing patients to increasing risk. Given that an elderly patient is healthy, it seems reasonable to stop surveillance at around 80 years of age.

There is very little evidence as to the efficacy of these published guidelines. A recent study reclassified patients from the Polyp Prevention Trial based on the findings at their initial colonoscopy into high and low risk as defined by the 2006 guidelines. At 4-year followup, the probability of advanced adenoma recurrence was $0.09 \%$ in patients with high-risk adenomas at baseline versus $0.05 \%$ in patients with low-risk adenomas at baseline. ${ }^{59}$ The relative risk for advanced adenoma recurrence in patients with high-risk baseline adenomas versus those with low-risk baseline adenomas was 1.68 $(\mathrm{CI}=1.19$ to 2.38). The authors conclude that although high-risk baseline adenomas confer greater risk of recurrence of advanced adenomas, the risk is not that much different from patients with low-risk baseline adenomas. Clearly, further research is needed to ensure optimal screening strategies are realized, providing patients with effective prevention of advanced adenomas and cancer, while minimizing exposure to frequent unnecessary tests with potential risks and complications.

\section{REFERENCES}

1. Rex DK, Lehman GA, Hawes RH, Ulbright TM, Smith JJ. Screening colonoscopy in asymptomatic average-risk persons with negative fecal occult blood tests. Gastroenterology 1991; 100:64-67

2. Rex DK, Lehman GA, Ulbright TM, et al. Colonic neoplasia in asymptomatic persons with negative fecal occult blood tests: influence of age, gender, and family history. Am J Gastroenterol 1993;88:825-831

3. Williams AR, Balasooriya BA, Day DW. Polyps and cancer of the large bowel: a necropsy study in Liverpool. Gut 1982; 23:835-842

4. Winawer SJ, Zauber AG, Ho MN, et al. Prevention of colorectal cancer by colonoscopic polypectomy. The National Polyp Study Workgroup. N Engl J Med 1993;329:1977-1981

5. Citarda F, Tomaselli G, Capocaccia R, Barcherini S, Crespi M. Efficacy in standard clinical practice of colonoscopic polypectomy in reducing colorectal cancer incidence. Gut 2001;48:812-815

6. Zubarik R, Ganguly E, Benway D, Ferrentino N, Moses P, Vecchio J. Procedure-related abdominal discomfort in patients undergoing colorectal cancer screening: a comparison of colonoscopy and flexible sigmoidoscopy. Am J Gastroenterol 2002;97:3056-3061

7. Levin TR, Zhao W, Conell C, et al. Complications of colonoscopy in an integrated health care delivery system. Ann Intern Med 2006;145:880-886

8. Gatto NM, Frucht H, Sundararajan V, Jacobson JS, Grann VR, Neugut AI. Risk of perforation after colonoscopy and sigmoidoscopy: a population-based study. J Natl Cancer Inst 2003;95:230-236
9. Rex DK, Bond JH, Winawer S, et al. Quality in the technical performance of colonoscopy and the continuous quality improvement process for colonoscopy: recommendations of the U.S. Multi-Society Task Force on Colorectal Cancer. Am J Gastroenterol 2002;97:1296-1308

10. Mandel JS, Church TR, Bond JH, et al. The effect of fecal occult-blood screening on the incidence of colorectal cancer. N Engl J Med 2000;343:1603-1607

11. Thiis-Evensen E, Hoff GS, Sauar J, Langmark F, Majak BM, Vatn MH. Population-based surveillance by colonoscopy: effect on the incidence of colorectal cancer. Telemark Polyp Study I. Scand J Gastroenterol 1999;34:414-420

12. Robertson DJ, Greenberg ER, Beach M, et al. Colorectal cancer in patients under close colonoscopic surveillance. Gastroenterology 2005;129:34-41

13. Alberts DS, Martinez ME, Roe DJ, et al. Lack of effect of a high-fiber cereal supplement on the recurrence of colorectal adenomas. Phoenix Colon Cancer Prevention Physicians' Network. N Engl J Med 2000;342:1156-1162

14. Schatzkin A, Lanza E, Corle D, et al. Lack of effect of a lowfat, high-fiber diet on the recurrence of colorectal adenomas. Polyp Prevention Trial Study Group. N Engl J Med 2000; 342:1149-1155

15. Levin B, Lieberman DA, McFarland B, et al. Screening and surveillance for the early detection of colorectal cancer and adenomatous polyps. A joint guideline from the American Cancer Society, the US Multi-Society Task Force on Colorectal Cancer, and the American College of Radiology. Gastroenterology 2008;134(5):1570-1595

16. Haseman JH, Lemmel GT, Rahmani EY, Rex DK. Failure of colonoscopy to detect colorectal cancer: evaluation of 47 cases in 20 hospitals. Gastrointest Endosc 1997;45:451-455

17. Hixson LJ, Fennerty MB, Sampliner RE, Garewal HS. Prospective blinded trial of the colonoscopic miss-rate of large colorectal polyps. Gastrointest Endosc 1991;37:125-127

18. Rex DK, Cutler CS, Lemmel GT, et al. Colonoscopic miss rates of adenomas determined by back-to-back colonoscopies. Gastroenterology 1997;112:24-28

19. Bressler B, Paszat LF, Vinden C, Li C, He J, Rabeneck L. Colonoscopic miss rates for right-sided colon cancer: a population-based analysis. Gastroenterology 2004;127:452456

20. Rex DK, Cutler CS, Lemmel GT, et al. Colonoscopic miss rates of adenomas determined by back-to-back colonoscopies. Gastroenterology 1997;112:24-28

21. Pickhardt PJ, Nugent PA, Mysliwiec PA, Choi JR, Schindler WR. Location of adenomas missed by optical colonoscopy. Ann Intern Med 2004;141:352-359

22. Winawer SJ, Zauber AG, O'Brien MJ, et al. Randomized comparison of surveillance intervals after colonoscopic removal of newly diagnosed adenomatous polyps. The National Polyp Study Workgroup. N Engl J Med 1993; 328:901-906

23. Pabby A, Schoen RE, Weissfeld JL, et al. Analysis of colorectal cancer occurrence during surveillance colonoscopy in the dietary Polyp Prevention Trial. Gastrointest Endosc 2005;61:385-391

24. Loeve F, Van Ballegooijen M, Boer R, Kuipers EJ, Habbema JD. Colorectal cancer risk in adenoma patients: a nation-wide study. Int J Cancer 2004;111:147-151

25. Farrar WD, Sawhney MS, Nelson DB, Lederle FA, Bond JH. Colorectal cancers found after a complete colonoscopy. Clin Gastroenterol Hepatol 2006;4:1259-1264 
26. Atkin W, Rogers $\mathrm{P}$, Cardwell C, et al. Wide variation in adenoma detection rates at screening flexible sigmoidoscopy. Gastroenterology 2004;126:1247-1256

27. Barclay RL, Vicari JJ, Doughty AS, Johanson JF, Greenlaw RL. Colonoscopic withdrawal times and adenoma detection during screening colonoscopy. N Engl J Med 2006;355: 2533-2541

28. Singh H, Turner D, Xue L, Targownik LE, Bernstein CN. Risk of developing colorectal cancer following a negative colonoscopy examination: evidence for a 10-year interval between colonoscopies. JAMA 2006;295:2366-2373

29. Kudo SE, Kashida H. Flat and depressed lesions of the colorectum. Clin Gastroenterol Hepatol 2005;3:S33S36

30. Muto T, Kamiya J, Sawada T, et al. Small "flat adenoma" of the large bowel with special reference to its clinicopathologic features. Dis Colon Rectum 1985;28:847-851

31. Hurlstone DP, Cross SS, Adam I, et al. A prospective clinicopathological and endoscopic evaluation of flat and depressed colorectal lesions in the United Kingdom. Am J Gastroenterol 2003;98:2543-2549

32. Soetikno RM, Kaltenbach T, Rouse RV, et al. Prevalence of nonpolypoid (flat and depressed) colorectal neoplasms in asymptomatic and symptomatic adults. JAMA 2008;299: 1027-1035

33. Matsui T, Yao T, Iwashita A. Natural history of early colorectal cancer. World J Surg 2000;24:1022-1028

34. Goto H, Oda Y, Murakami Y, et al. Proportion of de novo cancers among colorectal cancers in Japan. Gastroenterology 2006;131(1):40-46

35. Gono K, Obi T, Yamaguchi M, et al. Appearance of enhanced tissue features in narrow-band endoscopic imaging. J Biomed Opt 2004;9:568-577

36. Su MY, Hsu CM, Ho YP, Chen PC, Lin CJ, Chiu CT. Comparative study of conventional colonoscopy, chromoendoscopy, and narrow-band imaging systems in differential diagnosis of neoplastic and nonneoplastic colonic polyps. Am J Gastroenterol 2006;101:2711-2716

37. Chiu HM, Chang CY, Chen CC, et al. A prospective comparative study of narrow-band imaging, chromoendoscopy, and conventional colonoscopy in the diagnosis of colorectal neoplasia. Gut 2007;56:373-379

38. Tischendorf JJ, Wasmuth HE, Koch A, Hecker H, Trautwein C, Winograd R. Value of magnifying chromoendoscopy and narrow band imaging (NBI) in classifying colorectal polyps: a prospective controlled study. Endoscopy 2007;39:1092-1096

39. Rex DK, Helbig CC. High yields of small and flat adenomas with high-definition colonoscopes using either white light or narrow band imaging. Gastroenterology 2007; 133:42-47

40. Adler A, Pohl H, Papanikolaou IS, et al. A prospective randomised study on narrow-band imaging versus conventional colonoscopy for adenoma detection: does narrow-band imaging induce a learning effect? Gut 2008;57:59-64

41. East JE, Suzuki N, Stavrinidis M, Guenther T, Thomas HJ, Saunders BP. Narrow band imaging for colonoscopic surveillance in hereditary non-polyposis colorectal cancer. Gut 2008;57:65-70

42. Cotton PB, Durkalski VL, Pineau BC, et al. Computed tomographic colonography (virtual colonoscopy): a multicenter comparison with standard colonoscopy for detection of colorectal neoplasia. JAMA 2004;291:1713-1719
43. Rockey DC, Paulson E, Niedzwiecki D, et al. Analysis of air contrast barium enema, computed tomographic colonography, and colonoscopy: prospective comparison. Lancet 2005; 365: 305-311

44. Pickhardt PJ, Choi JR, Hwang I, et al. Computed tomographic virtual colonoscopy to screen for colorectal neoplasia in asymptomatic adults. N Engl J Med 2003;349: 2191-2200

45. Halligan S, Altman DG, Taylor SA, et al. CT colonography in the detection of colorectal polyps and cancer: systematic review, meta-analysis, and proposed minimum data set for study level reporting. Radiology 2005;237:893-904

46. Mulhall BP, Veerappan GR, Jackson JL. Meta-analysis: computed tomographic colonography. Ann Intern Med 2005;142:635-650

47. Rosman AS, Korsten MA. Meta-analysis comparing CT colonography, air contrast barium enema, and colonoscopy. Am J Med 2007;120:203-210

48. Vijan S, Hwang I, Inadomi J, et al. The cost-effectiveness of CT colonography in screening for colorectal neoplasia. Am J Gastroenterol 2007;102:380-390

49. Burt R, Jass J. Hyperplastic polyposis. In: Hamilton, SR, Aaltonen, LA, eds. Pathology \& Genetics of Tumours of the Digestive System. World Health Organization Classification of Tumours. Lyon: IARC Press; 2000

50. Winawer SJ, Zauber AG, Fletcher RH, et al. Guidelines for Colonoscopy Surveillance after Polypectomy: A Consensus Update by the US Multi-Society Task Force on Colorectal Cancer and the American Cancer Society. Gastroenterology 2006;130:1872-1885

51. Spencer RJ, Melton LJ III, Ready RL, Ilstrup DM. Treatment of small colorectal polyps: a population-based study of the risk of subsequent carcinoma. Mayo Clin Proc 1984;59:305-310

52. Van Stolk RU, Beck GJ, Baron JA, Haile R, Summers R. Adenoma characteristics at first colonoscopy as predictors of adenoma recurrence and characteristics at follow-up. The Polyp Prevention Study Group. Gastroenterology 1998;115: 13-18

53. Yang G, Zheng W, Sun QR, et al. Pathologic features of initial adenomas as predictors for metachronous adenomas of the rectum. J Natl Cancer Inst 1998;90:1661-1665

54. Martinez ME, Sampliner R, Marshall JR, Bhattacharyya AK, Reid ME, Alberts DS. Adenoma characteristics as risk factors for recurrence of advanced adenomas. Gastroenterology 2001;120:1077-1083

55. Avidan B, Sonnenberg A, Schnell TG, Leya J, Metz A, Sontag SJ. New occurrence and recurrence of neoplasms within 5 years of a screening colonoscopy. Am J Gastroenterol 2002;97:1524-1529

56. Bertario L, Russo A, Sala P, et al. Predictors of metachronous colorectal neoplasms in sporadic adenoma patients. Int J Cancer 2003;105:82-87

57. Bonithon-Kopp C, Piard F, Fenger C, et al. Colorectal adenoma characteristics as predictors of recurrence. Dis Colon Rectum 2004;47:323-333

58. Lieberman DA, Weiss DG, Harford WV, et al. Five-year colon surveillance after screening colonoscopy. Gastroenterology 2007;133:1077-1085

59. Laiyemo AO, Murphy G, Albert PS, et al. Postpolypectomy colonoscopy surveillance guidelines: predictive accuracy for advanced adenoma at 4 years. Ann Intern Med 2008;148: 419-426 
60. Greenberg ER, Baron JA, Tosteson TD, et al. A clinical trial of antioxidant vitamins to prevent colorectal adenoma. Polyp Prevention Study Group. N Engl J Med 1994; 331: 141-147

61. Baron JA, Beach M, Mandel JS, et al. Calcium supplements for the prevention of colorectal adenomas. Calcium Polyp Prevention Study Group. N Engl J Med 1999;340: 101-107

62. Baron JA, Cole BF, Sandler RS, et al. A randomized trial of aspirin to prevent colorectal adenomas. N Engl J Med 2003; 348:891-899

63. Atkin WS, Morson BC, Cuzick J. Long-term risk of colorectal cancer after excision of rectosigmoid adenomas. N Engl J Med 1992;326:658-662

64. Noshirwani KC, Van Stolk RU, Rybicki LA, Beck GJ. Adenoma size and number are predictive of adenoma recurrence: implications for surveillance colonoscopy. Gastrointest Endosc 2000;51:433-437

65. Fossi S, Bazzoli F, Ricciardiello $\mathrm{L}$, et al. Incidence and recurrence rates of colorectal adenomas in first-degree asymptomatic relatives of patients with colon cancer. Am J Gastroenterol 2001;96:1601-1604

66. Otchy DP, Ransohoff DF, Wolff BG, et al. Metachronous colon cancer in persons who have had a large adenomatous polyp. Am J Gastroenterol 1996;91:448-454

67. Nusko G, Mansmann U, Kirchner T, Hahn EG. Risk related surveillance following colorectal polypectomy. Gut 2002; $51: 424-428$
68. Walsh RM, Ackroyd FW, Shellito PC. Endoscopic resection of large sessile colorectal polyps. Gastrointest Endosc 1992; 38:303-309

69. Tamura S, Nakajo K, Yokoyama Y, et al. Evaluation of endoscopic mucosal resection for laterally spreading rectal tumors. Endoscopy 2004;36:306-312

70. Bories E, Pesenti C, Monges G, et al. Endoscopic mucosal resection for advanced sessile adenoma and early-stage colorectal carcinoma. Endoscopy 2006;38:231-235

71. Hurlstone DP, Sanders DS, Cross SS, et al. Colonoscopic resection of lateral spreading tumours: a prospective analysis of endoscopic mucosal resection. Gut 2004;53 1334-1339

72. Brooker JC, Saunders BP, Shah SG, Thapar CJ, Suzuki N, Williams CB. Treatment with argon plasma coagulation reduces recurrence after piecemeal resection of large sessile colonic polyps: a randomized trial and recommendations. Gastrointest Endosc 2002;55:371-375

73. Lieberman D, Nadel M, Smith RA, et al. Standardized Colonoscopy Reporting and Data System: Report of the Quality Assurance Task Group of the National Colorectal Cancer Roundtable. Gastrointest Endosc 2007;65:757766

74. Faigel DO, Pike IM, Baron TH, et al. Quality indicators for gastrointestinal endoscopic procedures: an introduction. Gastrointest Endosc 2006;63:S3-S9 